University of Nebraska - Lincoln

DigitalCommons@University of Nebraska - Lincoln

Faculty Publications: Department of Entomology

Entomology, Department of

$9-2015$

\title{
Evaluating sub-lethal effects of orchard-applied pyrethroids using video-tracking software to quantify honey bee behaviors
}

\author{
Erin M. Ingram \\ University of Nebraska-Lincoln, erin.michelle.ingram@gmail.com \\ Julie Augustin \\ Université d'Avignon et des pays du Vaucluse, Avignon \\ Marion D. Ellis \\ University of Nebraska-Lincoln, mellis3@unl.edu \\ Blair Siegfried \\ University of Nebraska-Lincoln, bsiegfried1@ufl.edu
}

Follow this and additional works at: https://digitalcommons.unl.edu/entomologyfacpub

Part of the Entomology Commons, Environmental Chemistry Commons, Environmental Health and Protection Commons, Natural Resources Management and Policy Commons, and the Other Environmental Sciences Commons

Ingram, Erin M.; Augustin, Julie; Ellis, Marion D.; and Siegfried, Blair, "Evaluating sub-lethal effects of orchard-applied pyrethroids using video-tracking software to quantify honey bee behaviors" (2015). Faculty Publications: Department of Entomology. 377.

https://digitalcommons.unl.edu/entomologyfacpub/377

This Article is brought to you for free and open access by the Entomology, Department of at DigitalCommons@University of Nebraska - Lincoln. It has been accepted for inclusion in Faculty Publications: Department of Entomology by an authorized administrator of DigitalCommons@University of Nebraska - Lincoln. 


\title{
Evaluating sub-lethal effects of orchard-applied pyrethroids using video-tracking software to quantify honey bee behaviors
}

\author{
Erin M. Ingram, ${ }^{1}$ Julie Augustin, ${ }^{2}$ Marion D. Ellis, ${ }^{1}$ and Blair D. Siegfried ${ }^{1}$ \\ 1. Department of Entomology, University of Nebraska-Lincoln, Lincoln, NE, USA \\ 2. Département d'Agronomie, Université d'Avignon et des pays du Vaucluse, Avignon, Provence Alpes Côtes d'Azur, France \\ Corresponding author - E.M. Ingram, Department of Entomology, 103 Entomology Hall, \\ University of Nebraska-Lincoln, Lincoln, NE 68583, USA; email erin.michelle.ingram@gmail.com
}

\begin{abstract}
Managed honey bee, Apis mellifera L., colonies are contracted to pollinate fruit and nut orchards improving crop quality and yield. Colonies placed in orchards are potentially exposed to pyrethroid insecticides used for broad-spectrum pest control. Pyrethroids have been reported to pose minimal risk to bees due to their low application rates in the field and putative repellent properties. This repellency is believed to alter foraging behavior with the benefit of preventing bees from encountering a lethal dose in the field. However, sub-lethal exposure to pyrethroids may adversely impact bee behavior potentially resulting in social dysfunction or disruption of foraging.

This study quantified behaviors associated with sub-lethal exposure to orchard-applied pyrethroids including, lambdacyhalothrin, esfenvalerate, and permethrin, using video tracking software, Ethovision XT (Noldus Information Technologies). Bee locomotion, social interaction, and time spent near a food source were measured over a 24-h period. Bees treated with a pyrethroid traveled $30-71 \%$ less than control bees. Social interaction time decreased by $43 \%$ for bees treated with a high sub-lethal dose of esfenvalerate. Bees exposed to a high sub-lethal dose of permethrin spent $67 \%$ less time in social interaction and spent more than 5 times as long in the food zone compared to control bees.
\end{abstract}

Keywords: Sublethal effects, Pyrethroids, Risk assessment, Honey bee, Video tracking, Behavior

\section{Introduction}

Honey bees, Apis mellifera, are important pollinators of agricultural crops and wild plants (Klein et al., 2007). Yet, this partnership is threatened in the U.S. as commercial beekeepers continue to struggle to maintain the health of colonies plagued by diverse afflictions including parasites, pathogens, beekeeping management practices, inadequate nutrition and exposure to pesticides (vanEngelsdorp et al., 2009; USDA CCD Steering Committee, 2012).

Pyrethroids are applied as broad-spectrum insecticides (Spurlock and Lee, 2008) in a variety of agricultural settings including on orchard crops (National Agricultural Statistics Service, 2012a). Current reports indicate pyrethroids are applied to nearly 1 million orchard acres in the U.S. including almonds, apples, apricots, sweet and tart cherries, peaches, plums, prunes, pears, and nectarines (California Environmental Protection Agency, 2011; National Agricultural Statistics Service, 2011, 2012a). The heaviest use of pyrethroids in orchards occurs in almond orchards with 85271 lbs. of active ingredients applied to 731442 acres in 2011 (California Environmental Protection Agency, 2011). The California Environmental Protection Agency reported a 39\% decrease in almond acres treated with permethrin, while acres treated with bifenthrin and esfenvalerate increased by $32 \%$ and 26\%, respectively in 2011 (California Environmental Protection Agency, 2011). This suggests that newer pyrethroid formulations are replacing older pyrethroid compounds. Regardless of which pyrethroid compound is applied, label restrictions prohibit application of agricultural pyrethroids on blooming crops or weeds or application is restricted to low application rates 
and evening application when bees are not present due to high toxicity (Riedl, 2006). As a result, pyrethroid applications are encouraged only during the dormant season or after bloom in the growing season to prevent exposure to non-target organisms including pollinators. Almonds are particularly dependent on managed honey bee colonies for adequate pollination (Delaplane and Mayer, 2000). In 2012, 780000 almond-bearing acres in California required an average of 2 colonies per acre for adequate pollination (Delaplane and Mayer, 2000; National Agricultural Statistics Service, 2012b). This single crop pollination event required the pollination services of 1.6 million colonies, or nearly $60 \%$ of all managed colonies accounted for in the U.S. The large number of colonies used for orchard pollination and the prevalence of pyrethroid applications on fruit and nut trees increases the likelihood of honey bee exposure to pyrethroids during orchard crop pollination events.

Despite efforts to minimize non-target exposure to pesticides, honey bees are exposed to various commercial agricultural pesticides and in-hive acaricides to control various honey bee pests (Johnson et al., 2010). Mullin et al. (2010) reported the presence of 121 different pesticides within hive components including wax, pollen, and bee samples with highly toxic, externally-derived pyrethroids being the most commonly detected insecticide class. Three orchard-applied pyrethroids of interest examined in this study, cyhalothrin, esfenvalerate, and permethrin, were detected in wax (at maximum levels of 17,56 , and $372 \mathrm{ppb}$, respectively), pollen (at maximum levels of 28,60 , and $92 \mathrm{ppb}$ ), and bee samples (at maximum levels of 2, 9, and 19600 ppb) (Mullin et al., 2010). In addition, eight different pyrethroids have been detected at ppb levels in pollen gathered during various crop pollination events including maximum levels of $131 \mathrm{ppb}$ of cyhalothrin and $216 \mathrm{ppb}$ of esfenvalerate in apple pollen (Pettis et al., 2013). The presence of agricultural or horticultural pyrethroids within the hive would suggest that foraging honey bees are exposed to these compounds in the field, and in some cases, return to contaminate the hive. Pyrethroid-treated orchards can expose foraging bees to contaminated pollen in the field, and the exposure extends to the hive environment when contaminated bees return to the hive with tainted pollen. Pollen is an important protein source for proper development of adult bees and developing larvae. Non-foraging colony members may be exposed during consumption of contaminated pollen.

Behavioral effects of pyrethroids were previously examined in the 1980's with compounds registered at that time including permethrin which was first registered by the United States Environmental Protection Agency (EPA) in 1979 (US EPA, 2011). However, esfenvalerate and lambda-cyhalothrin were registered by the EPA in 1986 and 1989, respectively (US EPA, 2009, 2010), and information on their sub-lethal behavioral impacts to honey bees is limited. This study provides data on behavioral effects of three pyrethroids that are currently applied to orchard crops.

This study aims to quantify effects of three pyrethroids currently used in orchard pest control, esfenvalerate, lambda-cyhalothrin, and permethrin, on worker honey bee behavior. We employed a video-tracking tool, Ethovision XT (Ver. 7.0, Noldus Information Technologies, Wageningen, Netherlands) to analyze bee behavior and to assess sub-lethal effects of pesticides on non-target organisms including honey bees. Following methods described by Teeters et al. (2012), we quantified distance moved in a 24-h period, time spent in social interaction with another worker bee, and time spent near food under laboratory conditions.

The EPA's recently amended pesticide risk assessment paradigm has expanded to evaluate chronic and acute exposure, multiple routes of exposure including ingestion and contact, and impacts on larval and adult life stages (US EPA et al., 2012). However, despite the fact that sub-lethal exposure to pesticides has been shown to impact individual honey bee learning, behavior, development, and longevity (Desneux et al., 2007), the new risk assessment endpoints are restricted to impaired survival, growth, and reproduction. The EPA states that until consistent and reproducible data can be collected to link sub-lethal effects to current assessment endpoints, sub-lethal measurements will only serve as a method for describing pesticide exposure effects on individual bees (US EPA et al., 2012). Nevertheless, video tracking provides a novel means of collecting quantitative, objective, and reproducible data on behavioral effects of pesticide exposure in a laboratory setting.

\section{Materials and methods}

\subsection{Chemicals}

Technical-grade 40:60 cis:trans permethrin (CAS\# 52645-53-1), esfenvalerate (CAS\# 66230-04-4), and lambda-cyhalothrin (CAS\# 91465-08-6) were obtained from Chem Service (West Chester, PA). Purity for all chemicals was $>98 \%$.

\subsection{Honey bees}

The test population of honey bees was selected from 2 of $16 \mathrm{col}-$ onies maintained in the University of Nebraska-Lincoln East Campus apiary. In April 2012, colonies were headed by Italian queens obtained from C.F. Koehnen and Sons of Glenn, California. Colonies were treated with the antibiotic Terramycin (oxytetracycline) to prevent bacterial brood diseases and the miticide, Mite Away Quick Strips (formic acid, NOD Global, Frankford, Ontario, Canada), to control for the parasitic mite, Varroa destructor.

Frames of emerging brood, or sealed brood within $24 \mathrm{~h}$ of eclosion were selected and moved to a laboratory incubator (model H024; Darwin Chambers, St. Louis, MO) maintained at $33^{\circ} \mathrm{C} \pm 2{ }^{\circ} \mathrm{C}$, with $>80 \%$ relative humidity and in the absence of light except during treatment and observation times. Adult bees were brushed from the frames daily after emergence into screened wooden boxes $(9 \mathrm{~cm} \times 10 \mathrm{~cm} \times 18 \mathrm{~cm})$ and fed a $50 \%$ sucrose/water solution ad libitum. Caged bees were then returned to the incubator to mature for 2 to $3 \mathrm{~d}$ prior to treatment and recording.

\subsection{Treatments}

Treatment of lambda-cyhalothrin, esfenvalerate, or permethrin was applied topically. Bees were treated with one of three sublethal doses for each pyrethroid tested: a high dose, equal to an estimated $\mathrm{LD}_{10}$ determined in preliminary bioassays; a moderate dose, equal to a 1:1 dilution of the high dose and acetone; a low dose, equal to a 1:10 dilution of the high dose and acetone. In addition, bees treated with acetone served as controls. Bees were treated with $0.00,1.28,6.39$, or $12.79 \mathrm{ng}$ of lambda-cyhalothrin, $0.00,2.60,12.98$, or 25.96 ng of esfenvalerate, or $0.00,5.23,26.15$, or $52.29 \mathrm{ng}$ of permethrin dissolved in acetone. Bees were anesthetized with carbon dioxide and one $\mu \mathrm{L}$ of solution was applied to the thoracic notum of the bee using a $50-\mu \mathrm{L}$ microsyringe attached to a repeating dispenser (model PB-600; Hamilton, Reno, NV).

\subsection{Video-tracking}

Bee behaviors were recorded with video-tracking software, Ethovision XT, as previously described by Teeters et al. (2012). Response variables measured included total distance moved, time spent in social interaction, and time spent near a food source. Thirty-two bees were recorded simultaneously by placing pairs of treated bees in 16 petri dishes partitioned by wire mesh. This maintained 
each bee in a separate arena for movement while allowing for interaction across the wire barrier. Each bee was provided with food and moisture via a $0.5 \times 1.0-\mathrm{cm}$ sucrose agar cube. A mixture of $8 \mathrm{~g}$ granulated cane sugar, $0.17 \mathrm{~g}$ agar powder, and $20 \mathrm{~mL}$ distilled water was brought to a boil, poured into a plastic tray with $1 \mathrm{~cm}^{2}$ sections, allowed to congeal, and refrigerated for a maximum of $7 \mathrm{~d}$ prior to use. Cubes were cut in half and placed in the petri dish prior to treatment of bees.

Following treatment, all petri dishes were randomly placed in a structure for recording and $26 \mathrm{~h}$ of video were recorded. The first and last hour of recording were not analyzed to allow for bees to recover from handling and anesthesia and to maintain 24-h continuity across all replicates.

A screenshot of each recording was used as a guide while areas of interest (i.e. arenas and food zones) and light contrast settings were manually-defined within Ethovision XT software allowing for automated tracking and quantification of recorded behaviors. The arena of bee movement corresponded to half a petri dish. The food zone was designated as a 30- × 15-pixel rectangle surrounding the sucrose food cube. Social interaction was assumed when bees were within $1.5 \mathrm{~cm}$ of one another and each bee was moving at a velocity of $<2 \mathrm{~cm} \mathrm{~s}^{-1}$.

A bee's location was tracked continuously at 15 samples per second as a series of $x, y$ coordinates in Ethovision XT software. Coordinates were converted to actual distance by translating pixel distance in the image to real world measurements by calibrating the software to the $9-\mathrm{cm}$ diameter of the petri dish. Coordinates were used to calculate total distance moved, amount of time spent in the food zone, and time spent within $1.5 \mathrm{~cm}$ of the neighboring bee. Due to low video resolution and camera distance from the bees, it cannot be confirmed that feeding occurred when bees were tracked inside the food zone, therefore, we characterize this behavior as time spent in the food zone rather than time spent feeding.

In one instance, a bee became stuck to the sucrose agar cube for a prolonged period and was not included in further analysis. In addition, bees that did not survive the total recording period were excluded from analysis.

\subsection{Data and statistical analysis}

A completely randomized design structure was implemented for video tracking. Data were gathered on a total of 128 bees per compound (four replications of 32 bees). Raw data were exported from Ethovision XT and compiled using R software (R Foundation for Statistical Computing, Vienna, Austria). Response variables, distance moved and time spent in social interaction, were log transformed to normalize the data and eliminate variance heterogeneity (Dowdy et al., 2004). The response variable, time spent in the food zone, was fit to a gamma distribution using a generalized linear model, as this was a more appropriate fit for the data. Statistical comparisons were made using a one-way analysis of variance (ANOVA) in SAS statistical software (Version 9.2, SAS Institute, Cary, $\mathrm{NC}$ ). When the overall effect of treatment was significant, pairwise mean comparisons of each dose level and control were performed using Dunnett's post hoc test (two-tailed) (Teeters et al., 2012). Results are reported as mean response \pm standard error.

\section{Results}

\subsection{Distance moved}

Movement of honey bees was significantly affected by exposure to all tested pyrethroids. Total distance moved was significantly reduced by exposure to all three pyrethroids at some of the doses tested [lambda-cyhalothrin $\left(p=0.0331, F_{3,104}=3.02\right)$, esfenvalerate $\left(p<0.0001, F_{3,118}=20.07\right)$, and permethrin $(p=0.0016$, $\left.\left.F_{3,122}=5.38\right)\right]$. Bees treated with a moderate dose $(6.39 \mathrm{ng})$ of lambda-cyhalothrin traveled $37 \%$ less $(159.7 \pm 25.7 \mathrm{~m} ; p=0.0107)$ on average than control bees $(255.5 \pm 39.7 \mathrm{~m}$ ) (Figure 1a). Bees exposed to esfenvalerate showed a decrease in total distance moved with increasing exposure. While the statistical analysis did not detect a significant decrease in distance moved at the lowest dose level $(2.60 \mathrm{ng})$, this group traveled $41 \%$ less than control bees $(254.6 \pm 33.2 \mathrm{~m}$ and $359.5 \pm 45.8 \mathrm{~m}$, respectively). Significant differences were detected at moderate (12.98 $\mathrm{ng}$ ) and high dose $(25.96 \mathrm{ng})$ levels of esfenvalerate in which bees moved $61 \%$ and $71 \%$ less on average (136.9 $\pm 16.1 \mathrm{~m} ; p<.0001$ and $103.7 \pm 14.8 \mathrm{~m}$; $p<.0001$, respectively) than control bees (Figure 1b). A 30\% decrease in distance moved was detected $(p=0.0064)$ for permethrin at the high dose of $52.29 \mathrm{ng}(161.9 \pm 28.5 \mathrm{~m})$ compared to the control bees $(232.1 \pm 28.0 \mathrm{~m}$ ) (Figure $1 \mathrm{c}$ ).
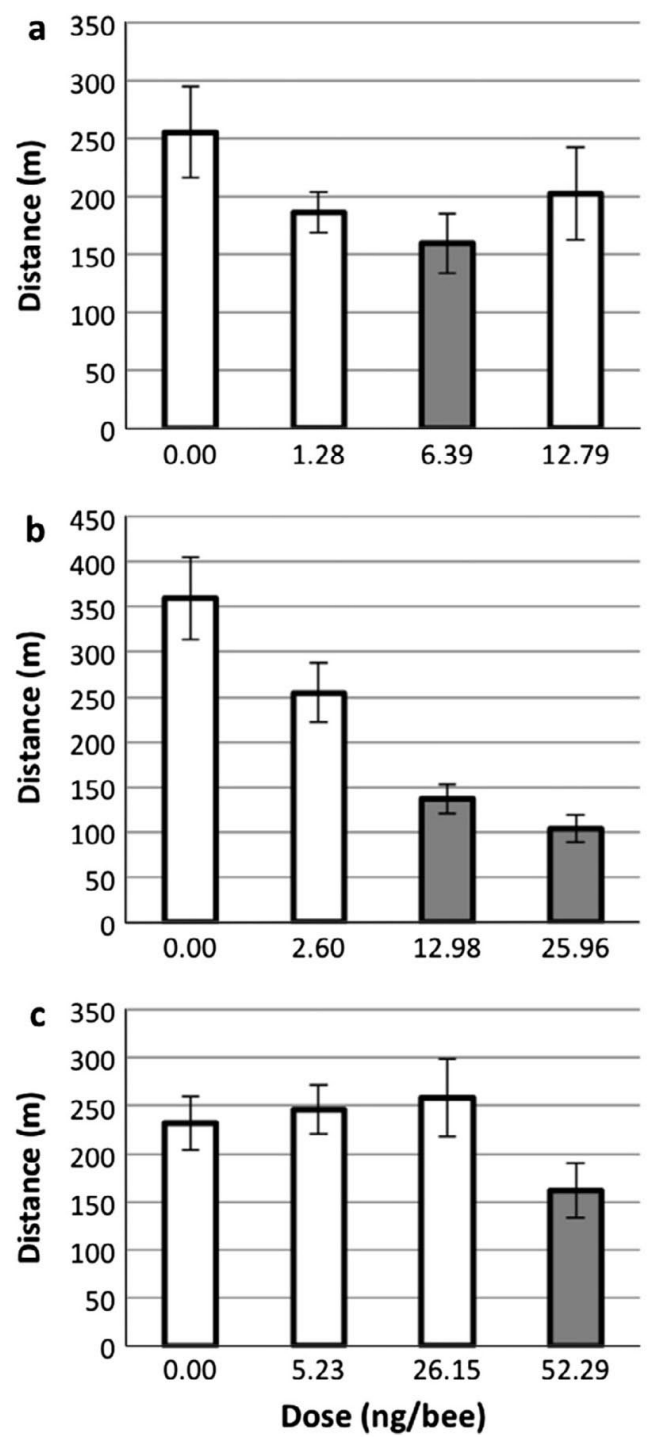

Figure 1. Effect of a single topical application of (a) lambda-cyhalothrin, (b) esfenvalerate, or (c) permethrin on distance moved by a honey bee over a 24-h period. Doses tested for lambda-cyhalothrin: acetone control $(n=31) ; 1.28$ $(n=32) ; 6.39(n=30)$; and $12.79 \mathrm{ng} /$ bee $(n=15)$. Doses tested for esfenvalerate: acetone control $(n=30) ; 2.60(n=31) ; 12.98(n=32) ;$ and $25.96 \mathrm{ng} / \mathrm{bee}$ $(n=29)$. Doses tested for permethrin: acetone control $(n=32) ; 5.23(n=32)$; $26.15(n=32)$; and $52.29 \mathrm{ng} /$ bee $(n=30)$. Shaded bars indicate significant differences from acetone control $(p<0.05)$. Values presented are mean response \pm standard error. 
a

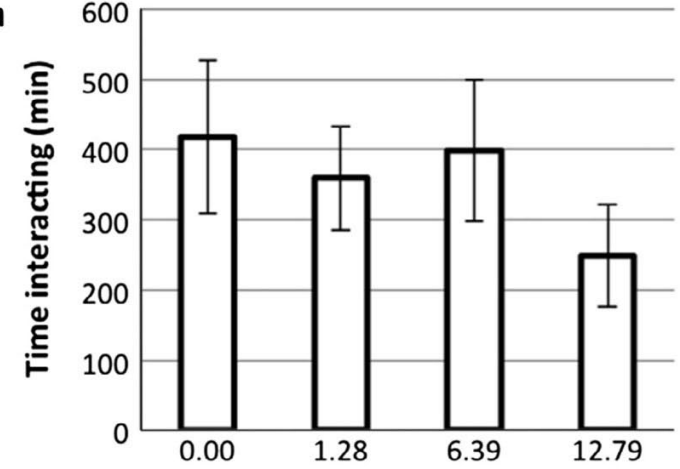

b

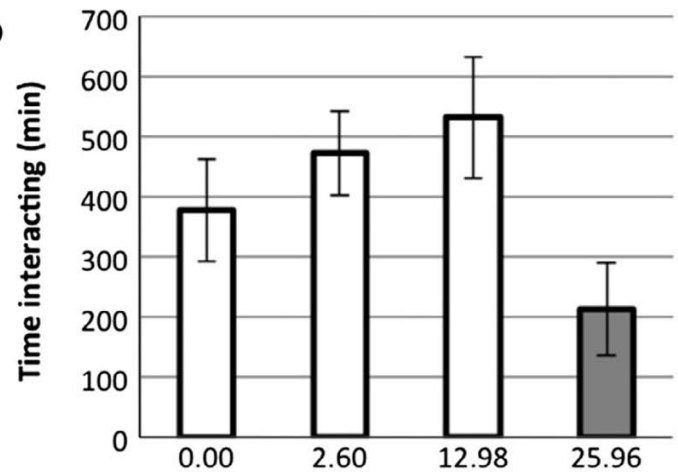

C

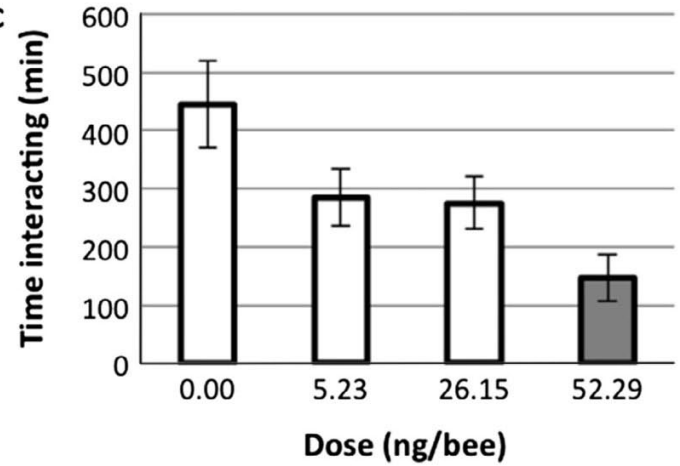

Figure 2. Effect of a single topical application of (a) lambda-cyhalothrin, (b) esfenvalerate, or (c) permethrin on social interaction of a pair of honey bees over a 24-h period. Doses tested for lambda-cyhalothrin: acetone control $(n=15)$; $1.28(n=16) ; 6.39(n=15)$; and $12.79 \mathrm{ng} / \mathrm{bee}(n=7)$. Doses tested for esfenvalerate: acetone control $(n=14) ; 2.60(n=15) ; 12.98(n=16) ;$ and $25.96 \mathrm{ng} /$ bee $(n=13)$. Doses tested for permethrin: acetone control $(n=16) ; 5.23(n=16)$; 26.15 ( $n=16)$; and $52.29 \mathrm{ng} /$ bee $(n=15)$. Shaded bars indicate significant differences from acetone control $(p<0.05)$. Values presented are mean response \pm standard error.

\subsection{Time spent in social interaction}

Social interaction time was significantly impacted by exposure to esfenvalerate $\left(p=0.0183, F_{3,54}=3.64\right)$ and permethrin $(p=0.0002$, $\left.F_{3,59}=7.69\right)$. However, there was no evidence of a treatment effect of lambda-cyhalothrin ( $p=0.6621, F_{3,49}=0.53$ ) (Figure $2 a$ ). Bees treated with esfenvalerate showed a $43 \%$ decrease in time spent in social interaction at the highest dose level of $25.96 \mathrm{ng}$ (212.96 $\pm 76.83 \mathrm{~min} ; p=0.0390)$ when compared to control bees (377.76 $\pm 85.24 \mathrm{~min}$ ) (Figure $2 \mathrm{~b})$. A 67\% decrease $(p=0.0004)$ in social interaction time was observed in bees treated with the highest dose level of permethrin, $25.96 \mathrm{ng}$ (146.65 $\pm 39.89 \mathrm{~min}$ ) compared to control bees (444.99 $\pm 74.33 \mathrm{~min}$ ) (Figure $2 \mathrm{c}$ ). a

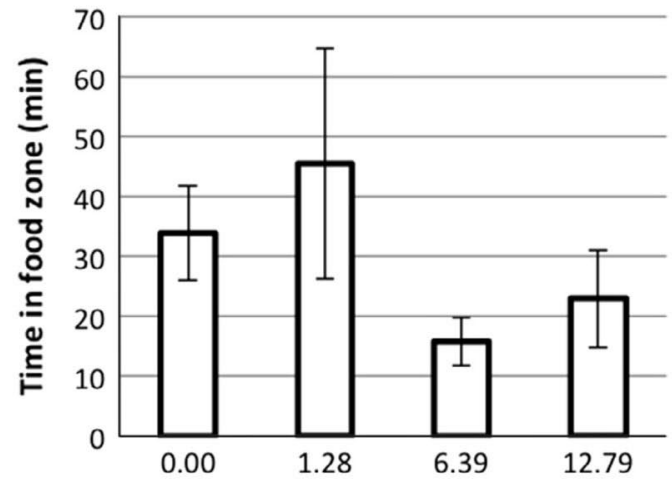

b
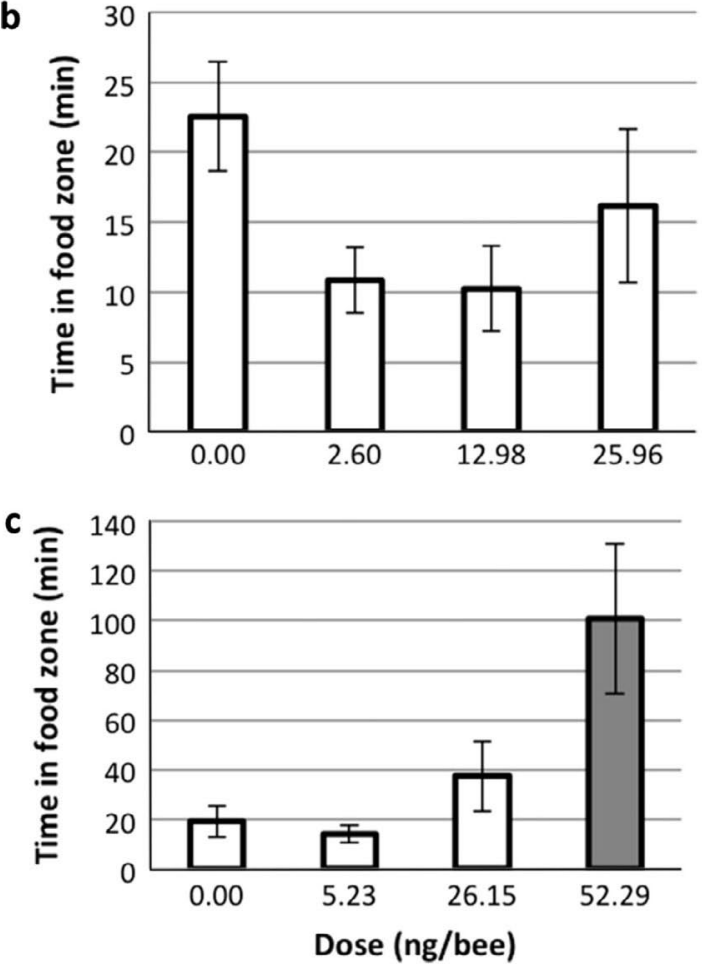

Figure 3. Effect of a single topical application of (a) lambda-cyhalothrin, (b) esfenvalerate, or (c) permethrin on time spent in the food zone by a honey bee over a 24-h period. Doses tested for lambda-cyhalothrin: acetone control $(n=31) ; 1.28(n=32) ; 6.39(n=30) ;$ and $12.79 \mathrm{ng} /$ bee $(n=15)$. Doses tested for esfenvalerate: acetone control $(n=30) ; 2.60(n=31) ; 12.98(n=32)$; and $25.96 \mathrm{ng} /$ bee $(n=28)$. Doses tested for permethrin: acetone control $(n=32)$; $5.23(n=32) ; 26.15(n=32)$; and $52.29 \mathrm{ng} /$ bee $(n=30)$. Shaded bars indicate significant differences from acetone control $(p<0.05)$. Values presented are mean response \pm standard error.

\subsection{Time spent in food zone}

A significant effect on the amount of time spent in the food zone was observed for lambda-cyhalothrin $\left(p=0.0274, F_{3,103}=3.17\right)$ and permethrin $\left(p<0.0001, F_{3,122}=13.25\right)$ while a marginally significant effect was observed for esfenvalerate $(p=0.0786$, $F_{3,117}=2.32$ ). Pair-wise comparisons of control versus treated groups indicated an increase in time spent in the food zone at the highest dose level for permethrin. Pyrethroid exposure did not produce a consistent response to food; time near the food cube appeared to decrease with exposure to lambda-cyhalothrin and esfenvalerate and increase with exposure to permethrin. Bees treated with a moderate dose (6.39 ng) of lambda-cyhalo- 
thrin spent less time $(16.37 \pm 4.13 \mathrm{~min} ; p=0.1049)$ in the food zone than control bees (33.92 $\pm 7.87 \mathrm{~min}$ ) although this difference was not statistically significant at $p<0.05$ (Figure 3a). Time spent in the food zone decreased for esfenvalerate-treated bees at the low $(2.60 \mathrm{ng})$ and moderate $(12.98 \mathrm{ng})$ dose treatment levels $(10.87 \pm 2.62 \mathrm{~min} ; p=0.0911$ and $10.23 \pm 2.42 \mathrm{~min} ; p=0.0578$, respectively) compared to control bees (22.53 $\pm 5.51 \mathrm{~min}$ ) (Figure $3 b)$. Again, this difference was not significant at $p<0.05$ due to conservative adjustments of Dunnett's post hoc test. Bees treated with a high dose of permethrin (52.29 ng) spent a significantly longer period in the food area $(100.94 \pm 24.46 \mathrm{~min} ; p<0.0001)$ relative to control bees (19.25 $\pm 4.52 \mathrm{~min}$ ) (Figure $3 \mathrm{c}$ ).

\section{Discussion}

The objective of this study was to assess sub-lethal effects of three orchard-applied pyrethroids using video tracking software, Ethovision XT, to quantify honey bee behaviors. Ethovision XT detected differences in locomotion, time spent in social interaction, and time spent in the food zone following exposure to a moderate or high sub-lethal dose of pyrethroids.

Bees treated with the highest dose level of permethrin exhibited decreased locomotion compared to control bees confirming results of previous manual tracking reported by Cox and Wilson (1984) in which bees treated with permethrin spent less time walking than untreated bees. Teeters et al. (2012) also observed a decrease in total distance moved in response to a sub-lethal dose of tau-fluvalinate, the pyrethroid found in Apistan ${ }^{\circledR}$, a beekeeperapplied acaricide for control of Varroa parasites. Our study noted a similar trend of decreasing locomotion following pyrethroid exposure for lambda-cyhalothrin and esfenvalerate. This study provides evidence that esfenvalerate and lambda-cyhalothrin elicit a similar effect on locomotion as permethrin and tau-fluvalinate. Decreased movement may be the result of treated bees experiencing typical symptoms of pyrethroid exposure including loss of coordinated movement, convulsions, and paralysis (Soderlund and Bloomquist, 1989). Additionally, honey bees may be replacing exploratory movement in the arena with relatively stationary grooming behaviors as noted by Cox and Wilson (1984).

Cox and Wilson (1984) also reported that bees treated with permethrin spent less time in antennal probing and food giving behavior than control bees. Our findings support this observation as bees treated with the highest dose of permethrin spent less time in social interaction with another bee than control bees. The highest dose level of esfenvalerate elicited a similar response in treated bees; however, no effect on social interaction was observed for lambda-cyhalothrin indicating that not all pyrethroids have the same degree of behavioral impact on social interaction.

Additionally, time spent in the food zone was variable in response across chemicals. Our results indicated that at the highest dose of permethrin, treated bees spent more time in the food zone than untreated bees. Conversely, this trend was not observed with esfenvalerate- and lambda-cyhalothrin-treated bees, which spent less time in the food zone than untreated bees. Although the results for esfenvalerate- and lambda-cyhalothrin-treated bees were not significant at $p<0.05$, the data exhibited numerical differences as low- and moderately-treated bees spent approximately half as much time in the food zone as control bees. Typically, pyrethroids are classified as Type I or II compounds based on differences in structure and intoxication symptoms (Soderlund and Bloomquist, 1989; Yu, 2008). Permethrin is classified as a Type I compound while esfenvalerate and lambda-cyhalothrin are grouped with Type II compounds. While differing symptoms in insects are less clearly defined than in mammals (Soderlund and Bloomquist, 1989), differences in intoxication from exposure to Type I versus Type II pyrethroids may explain inconsistencies in behavioral response to food across the three pyrethroids tested.

While this study attempts to simulate topical exposure to fieldapplied insecticides, the topical treatment protocol used in this assay requires the test subjects to unavoidably encounter a known dose of purified toxicant in an acetone solution, and behavior is tracked under conditions that do not simulate a hive environment. As a consequence, the laboratory assay used in this investigation does not equate to a field evaluation of pyrethroid exposure but rather should be considered a worst-case scenario of exposure (Decourtye and Pham-Delegue, 2002). Despite these limitations, video tracking under laboratory conditions allows for greater control over application of treatment and environmental conditions. In addition, video tracking quantifies bee behavior providing objective, precise, and predictive data on the effects of pesticide exposure.

Finally, further testing with additional hives could provide a better sense of colony variation in response to pyrethroid exposure. The scope of this study was limited to two hives, and it is possible that genetic differences between hives may account for differences in pyrethroid tolerance. During this study, we noted increased mortality of bees from one hive when exposed to a high sub-lethal dose of lambda-cyhalothrin. With these individuals removed from analysis, it would appear that lambda-cyhalothrin does not produce a dose dependent effect. However, this trend may be an artifact of data being collected on bees with less sensitivity to this compound. Additionally, a variety of environmental or hive conditions including physiological differences across seasons (Wahl and Ulm, 2004), temperature (Johansen and Mayer, 1990, p. 70), age of bees (Johansen and Mayer, 1990, p. 80), presence of pests, parasites, or diseases (Vidau et al., 2011), nutritional state (Wahl and UIm, 2004), and exposure to P450-inhibiting fungicides (Johnson et al., 2009) may impact the ability of bees to tolerate exposure to chemicals encountered in their environment. These differences may influence their level of intoxication, and in turn, their behavioral response following pesticide exposure. Future studies could examine effects on bee behavior across seasons or in the presence of multiple biotic or abiotic stresses to gain an understanding of potential interactions.

\section{Conclusions}

Video tracking effectively detected differences in locomotion, social interaction, and food associations following sub-lethal pyrethroid exposure. While this study did not correlate sub-lethal behavioral effects with risk assessment endpoints or colony-level impacts, it demonstrated that video tracking can be used to quantify bee behaviors. The measurements reported in this study allow objective and repeatable examination of the effects of sub-lethal pesticide exposure on individual honey bees.

Acknowledgments - We would like to recognize Dr. Reed Johnson at The Ohio State University for use of his R code making our large data sets manageable; Bethany Teeters for her guidance in using the Ethovision XT system; Travis Hinkelman and Elizabeth Claassen for aiding in statistical analysis; and to the Richard P. Kimmel and Laurine Kimmel Charitable Foundation for their financial support of this project.

\section{References}

California Environmental Protection Agency, 2011. Summary of Pesticide Use Report Data. California Environmental Protection Agency, Department of Pesticide Regulation, Sacramento, CA. 
Cox, R.L., Wilson, W.T., 1984. Effects of permethrin on the behavior of individually tagged honey bees, Apis mellifera L. (Hymenoptera: Apidae). Environ. Entomol. 13, 375-378.

Decourtye, A., Pham-Delegue, M.H., 2002. Assessing the sublethal effects of pesticides on the honey bee. In: Honey Bees: Estimating the Environmental Impact of Chemicals. Taylor \& Francis, New York, pp. 67-84.

Delaplane, K.S., Mayer, D.F., 2000. Crop Pollination by Bees. CABI Pub, New York.

Desneux, N., Decourtye, A., Delpuech, J., 2007. The sublethal effects of pesticides on beneficial arthropods. Annu. Rev. Entomol. 52, 81106. doi: 10.1146/annurev.ento.52.110405.091440.

Dowdy, S., Wearden, S., Chilko, D., 2004. Statistics for research. In: Wiley Series in Probability and Statistics, third ed. John Wiley \& Sons, Hoboken, NJ.

Johansen, C.A., Mayer, D.F., 1990. Pollinator Protection: a Bee \& Pesticide Handbook. Wicwas Press, Cheshire, CT.

Johnson, R.M., Pollock, H.S., Berenbaum, M.R., 2009. Synergistic interactions between in-hive Miticides in Apis mellifera. J. Econ. Entomol. 102, 474-479. doi: 10.1603/029.102.0202.

Johnson, R., Ellis, M., Mullin, C., Frazier, M., 2010. Pesticides and honey bee toxicity-USA. Apidologie 41, 312-331. doi: 10.1051/ apido/2010018.

Klein, A.-M., Vaissière, B.E., Cane, J.H., Steffan-Dewenter, I., Cunningham, S.A., Kremen, C., Tscharntke, T., 2007. Importance of pollinators in changing landscapes for world crops. Proc. R. Soc. B Biol. Sci. 274, 303-313. doi: 10.1098/rspb.2006.3721.

Mullin, C.A., Frazier, M., Frazier, J.L., Ashcraft, S., Simonds, R., vanEngelsdorp, D., Pettis, J.S., 2010. High levels of miticides and agrochemicals in North American apiaries: implications for honey bee health. PLoS ONE 5, e9754. doi:10.1371/journal.pone.0009754.

National Agricultural Statistics Service, 2011. Survey of National FruitBearing Acres. United States Department of Agriculture, Sacramento, CA.

National Agricultural Statistics Service, 2012a. Chemical Use on Fruit. United States Department of Agriculture, Sacramento, CA, USA.

National Agricultural Statistics Service, 2012b. California Almond Objective Measurement Report. USDA, Sacramento, CA.

Pettis, J.S., Lichtenberg, E.M., Andree, M., Stitzinger, J., Rose, R., van Engelsdorp, D., 2013. Crop pollination exposes honey bees to pesticides which alters their susceptibility to the gut pathogen, Nosema ceranae. PLoS ONE 8, e70182. doi: 10.1371/journal.pone.0070182.
Riedl, H., 2006. How to Reduce Bee Poisoning from Pesticides. University of California Agriculture \& Natural Resources.

Soderlund, D.M., Bloomquist, J.R., 1989. Neurotoxic actions of pyrethroid insecticides. Annu. Rev. Entomol. 34, 77-96. doi: 10.1146/ annurev.en.34.010189.000453.

Spurlock, F., Lee, M., 2008. Synthetic pyrethroid use patterns, properties, and environmental effects. In: Synthetic Pyrethroids: Occurrence and Behavior in Aquatic Environments (Gan J, Spurlock G, Hendley P, Weston D, Eds). ACS Symposium Series. pp. 3-25.

Teeters, B.S., Johnson, R.M., Ellis, M.D., Siegfried, B.D., 2012. Using video-tracking to assess sublethal effects of pesticides on honey bees (Apis mellifera L.). Environ. Toxicol. Chem. 31, 1349-1354. doi: 10.1002/etc.1830.

US EPA, 2009. Esfenvalerate Summary Document.

US EPA, 2010. Lambda-Cyhalothrin and Gamma-Cyhalothrin Summary Document.

US EPA, 2011. Permethrin Summary Document.

US EPA, Health Canada, California Department of Pesticide Regulation, 2012. White Paper in Support of the Proposed Risk Assessment Process for Bees. Submitted to the FIFRA Science Advisory Panel, Washington, D.C.

USDA CCD Steering Committee, 2012. Colony Collapse Disorder Progress Report. United States Department of Agriculture.

vanEngelsdorp, D., Evans, J.D., Saegerman, C., Mullin, C., Haubruge, E., Nguyen, B.K., Frazier, M., Frazier, J., Cox-Foster, D., Chen, Y., Underwood, R., Tarpy, D.R., Pettis, J.S., 2009. Colony collapse disorder: a descriptive study. PLoS ONE 4, e6481. doi: 10.1371/journal.pone.0006481.

Vidau, C., Diogon, M., Aufauvre, J., Fontbonne, R., Viguès, B., Brunet, J.-L., Texier, C., Biron, D.G., Blot, N., El Alaoui, H., Belzunces, L.P., Delbac, F., 2011. Exposure to sublethal doses of Fipronil and Thiacloprid highly increases mortality of honeybees previously infected by Nosema ceranae. PLoS ONE 6, e21550. doi: 10.1371/ journal.pone.0021550.

Wahl, O., Ulm, K., 2004. Influence of pollen feeding and physiological condition on pesticide sensitivity of the honey bee, Apis mellifera carnica. Oecologia 59, 106-128. doi: 10.1007/BF00388082.

Yu, S.J., 2008. The Toxicology and Biochemistry of Insecticides. CRC Press/Taylor \& Francis, Boca Raton, FL. 